Review Article

\section{Risk factor of liver metastases in}

\section{breast cancer}

\author{
Akram Yazdani* \\ Department of Epidemiology and Biostatistics, School of Public Health, Tehran University of \\ Medical Sciences, Tehran, Iran
}

\section{Abstract}

Objective: The liver is the second most common site of distant metastases from breast cancer. We investigated the risk factor liver metastasis in patients with breast cancer.

Methods: We studied Age, Menopausal status, Histologic Type, Tumor size, Number of cancerous axillary lymph nodes, in two groups with liver metastases with logistic regression to identify independent liver metastasis risk factors in breast cancer patients.

Results: Age, menopausal status, number of cancerous axillary lymph nodes and tumor size are the independent risk factors liver metastases in patients with breast cancer.

Conclusion: The increase number of cancerous axillary lymph nodes and tumor size may be diagnostic markers for liver metastases from breast cancer.

\section{More Information}

*Address for Correspondence: Akram Yazdani, Department of Epidemiology and Biostatistics, School of Public Health, Tehran University of Medical Sciences, Tehran, Iran,

Tel: 989132274186;

Email: Akram.yazdani@gmail.com

Submitted: 25 June 2019

Approved: 10 December 2019

Published: 11 December 2019

How to cite this article: Yazdani A. Risk factor of liver metastases in breast cancer. Arch Cancer Sci Ther. 2019; 3: 063-065.

DOI: dx.doi.org/10.29328/journal.acst.1001011

Copyright: (C) 2019 Yazdani A. This is an open access article distributed under the Creative Commons Attribution License, which permits unrestricted use, distribution, and reproduction in any medium, provided the original work is properly cited.

Keywords: Liver metastases; Breast cancer; Prognostic factor

(W) Check for updates

OPEN ACCESS

\section{Introduction}

Breast cancer is the most frequent malignancy and most common cause of cancer-related death in women worldwide. Despite advances in the treatment of early breast cancer, approximately $20 \%$ - 30\% of patients will relapse with distant metastases. Metastatic breast cancer is a heterogeneous disease with a variety of clinical presentations ranging from a single metastatic lesion to diffuse and multiple organ involvement. The risk of recurrence and the distinct patterns of metastatic spread are not only influenced by stage at initial presentation, but are also associated with the molecular subtype of the primary tumour.

Liver metastases from breast cancer may present asymptomatically in a metastatic screen, or may present with upper abdominal fullness, ascites, a mass, jaundice or weight loss and detected much later and bring about worse prognoses [1-4]. A final diagnosis of early LM from BC is difficult. Thus, it is helpful to find a way to early diagnosis LM in patients with BC. It may lead to timely intervention and may prevent pathologic liver fracture. The purpose of the present study is evaluating risk factor liver metastasis in patients with breast cancer.

\section{Materials and Methods}

Demographic and clinical data, including Age, Menopausal status, Histologic Type, Number of cancerous axillary lymph nodes, Tumor size, were extracted from the patients' medical records. Then, associating above factors with LM in
BC patients was investigated. Statistical analyzes, including mean ( \pm standard deviations) for continuous variables and percentages for categorical variables were calculated using SPSS 19.0 software (Chicago, USA). Initially, patients with BC were divided into 2 groups: with LM and without it. To detecting the differences between two groups, MannWhitney U test and Chi-Square test were used. We applied logistic regression to identify independent prognostic factors. Statistical significance was set as a $p$ - value less than 0.05 .

\section{Results}

This study included 600 patients with BC and a total of $28.8 \%$ of them had LM. Clinical features of patients (Tables $1,2)$. The results showed that the age of patients with LM (45.55 $( \pm 10.77)$ ) was significantly higher than the age of patients without LM $(48.37( \pm 11.98))(p-$ value $=0.019)$. Moreover, there was a remarkable difference in the incidence of LM between different tumor sizes ( $p$ - value $<0.001$ ).

\section{Discussion}

$\mathrm{BC}$ has an understandable tendency to distance metastasis like the lymph nodes, liver, bones, and lungs [5-12]. LM sometimes shows the presence of distended cancer with weak prognosis, though it is restricted to one organ [3]. Early identification of LMs in BC patients maybe result in timely intervention and presumably stop pathologic liver problems. 
Table 1: The characteristics and clinical factors of patients with and without liver metastases from breast cancer.

\begin{tabular}{|c|c|c|c|c|}
\hline \multicolumn{2}{|c|}{ Prognostic Factors } & $\begin{array}{c}\text { Patients with } \\
\text { LM }\end{array}$ & $\begin{array}{c}\text { Patients } \\
\text { without }\end{array}$ & $p$ - value \\
\hline & & \multicolumn{3}{c|}{ Mean \pm SD } \\
\hline Age (years) mean \pm SD & $45.55 \pm 10.77$ & $48.37 \pm 11.98$ & $0.019^{*}$ \\
\hline Menopausal status $(n)$ & Premenopausal & 85 & 239 & $0.022^{*}$ \\
\cline { 2 - 5 } & Postmenopausal & 64 & 189 & $<0.001^{*}$ \\
\hline $\begin{array}{c}\text { Axillary lymph node } \\
\text { metastases }(n)\end{array}$ & $17 \pm 2.33$ & $21 \pm 1.77$ & $<0.001^{\star}$ \\
\hline Tumor size $(n)$ & $1.51 \pm 3.22$ & $2.17 \pm 2.21$ & $<0$ \\
\hline
\end{tabular}

Table 2: Risk factors for predicting liver metastases in patients with breast cancer.

\begin{tabular}{|c|c|c|c|c|c|}
\hline \multicolumn{1}{|c|}{ Factors } & B & OR & OR (95\% CI) & p - value \\
\hline \multicolumn{1}{|c|}{ Age } & 0.057 & 1.088 & $1.04-1.01$ & 0.020 \\
\hline Menopausal status & Postmenopausal & 0.203 & 1.027 & $1.01-3.01$ & 0.023 \\
\hline \multirow{2}{*}{$\begin{array}{c}\text { Axillary lymph node } \\
\text { metastases }\end{array}$} & 1.003 & 2.906 & $1.001-4.042$ & 0.001 \\
\cline { 2 - 6 } & & 0.821 & 1.512 & $0.817-5.882$ & 0.053 \\
\hline
\end{tabular}

Mann-Whitney test and logistic regression showed that age and menopausal status are prognostic factors for LM, as 1-year increase in age the risk of LM was increased. Also menopausal women are 1.827 times more likely to have LMs than premenopausal women. It is implied that elderlies, and postmenopausal patients are more likely to have a higher risk of LMs. There was no significant difference between ductal types in the groups with and without LMs. The number of axillary nodes of metastases and tumor size appear an important prognostic factors for LMs in BC. The generalizability of these results is subject to several limitations [13-20].

First, the study was conducted by relying on only one database of an organization, although the criteria were designed to cover minimizing selection bias. Second, the study was retrospective and some clinical data were missing, which may affect the results of the analysis. Also, we just collected information from patients with $\mathrm{BC}$ at the time of diagnosis and the study did not include any data, such as patient survival rates and follow-up treatment data. Therefore, a multi-center, prospective study is suggested to be conducted to assess the results of this study [20-25].

\section{Conclusion}

Age, menopausal status, number of axillary lymph node metastases, tumor size. It can be beneficial in early diagnosis of $\mathrm{LMs}$ from $\mathrm{BC}$ and prevention and treatment of the disease.

\section{References}

1. Jemal A, Siegel R, Xu J. Cancer statistics CA. Cancer J Clin. 2010; 60: 277-300.

PubMed: https://www.ncbi.nlm.nih.gov/pubmed/20610543

2. Er $\mathrm{O}$ et al. Clinical course of breast cancer patients with metastases limited to the liver treated with chemotherapy. Cancer J. 2008; 14: 62-68. PubMed: https://www.ncbi.nlm.nih.gov/pubmed/18303485

3. Cao R, Wang L. Serological Diagnosis of Liver Metastasis in Patients with Breast Cancer. Cancer Biol Med. 2012; 9: 57-62.

PubMed: https://www.ncbi.nlm.nih.gov/pubmed/23691457
4. Wyld L, Gutteridge E, Pinder S. Prognostic factors for patients with hepatic metastases from breast cancer. Br J Cancer. 2003; 89: 284-290. PubMed: https://www.ncbi.nlm.nih.gov/pubmed/12865918

5. Saad R, Luckasevic T, Noga C, Johnson D, Silverman J. Diagnostic value of HepPar1, pCEA, CD10, and CD34 expression in separating hepatocellular carcinoma from metastatic carcinoma in fineneedle aspiration cytology. Diagn Cytopathol. 2004; 30: 1-6.

PubMed: https://www.ncbi.nlm.nih.gov/pubmed/14696137

6. Harris L, Fritsche H, Mennel R, Norton L, Ravdin P, et al. American Society of Clinical Oncology 2007 update of recommendations for the use of tumor markers in breast cancer. J Clin Oncol. 2007; 25: 5287-5312. PubMed: https://www.ncbi.nlm.nih.gov/pubmed/17954709

7. Nicolini A, Colombini C, Luciani L, Carpi A, Giuliani L. Evaluation of serum CA15-3 determination with CEA and TPA in the post-operative follow-up of breast cancer patients. Br J Cancer. 1991; 64: 154-158. PubMed: https://www.ncbi.nlm.nih.gov/pubmed/1854615

8. Lee J, Park S, Park J, Cho J, Kim S, et al. Elevated levels of preoperative CA 15-3 and CEA serum levels have independently poor prognostic significance in breast cancer. Ann Oncol. 2013; 25: 1225-1231. PubMed: https://www.ncbi.nlm.nih.gov/pubmed/23230137

9. Prabasheela B, Baskaran S, Arivazhagan R. Evaluation of alkaline phosphatase in pre and post operative breast cancer patients Short report Evaluation of alkaline phosphatase in pre and post operative breast cancer patients. Int J Biol Med Res. 2012; 3: 1536-1537.

10. Keshaviah A, Dellapasqua S, Rotmensz N, Lindtner J, Crivellari D, et al. CA15-3 and alkaline phosphatase as predictors for breast cancer recurrence : a combined analysis of seven International Breast Cancer Study Group trials. Ann Oncol. 2007; 18: 701-708.

PubMed: https://www.ncbi.nlm.nih.gov/pubmed/17237474

11. Crivellari $D$, Price $K$, Hagen M. Routine tests during follow-up of patients afterprimarytreatmentforoperablebreastcancer.International(Ludwig) Breast Cancer Study Group (IBCSG). Ann Oncol. 1995; 6: 769-776. PubMed: https://www.ncbi.nlm.nih.gov/pubmed/8589013

12. Selzner M, Morse MA, Vredenburgh JJ, Meyers WC. Liver metastases from breast cancer: Long-term survival after curative resection. Surgery. 2000; 127: 383-389.

PubMed: https://www.ncbi.nlm.nih.gov/pubmed/10776428

13. Liska V, Holubec L Jr, Treska V, Vrzalova J, Skalicky T, et al. Evaluation of Tumour Markers as Differential Diagnostic Tool in Patients with Suspicion of Liver Metastases from Breast Cancer. Anticancer Res. 2011; 31: 1447-1451.

PubMed: https://www.ncbi.nlm.nih.gov/pubmed/21508401

14. Al-Jarallah M, Behbehani A, El-Nass SA, Temim L, Ebraheem AK. Serum CA-15.3 and CEA patterns in postsurgical follow-up, and in monitoring clinical course of metastatic cancer in patients with breast carcinoma. Eur J Surg Oncol. 1993; 19: 74-79.

PubMed: https://www.ncbi.nlm.nih.gov/pubmed/8436243

15. Yerushalmi R. Tumor markers in metastatic breast cancer subtypes: frequency of elevation and correlation with outcome. Ann Oncol. 2012; 23: 338-345

PubMed: https://www.ncbi.nlm.nih.gov/pubmed/21543625

16. Huang P, Lan M, Peng A, Qing-fu Y, Wen-zhao C, et al. Serum calcium, alkaline phosphotase and hemoglobin as risk factors for bone metastases in bladder cancer. PLoS One. 2017; 12: 1-8. PubMed: https://www.ncbi.nlm.nih.gov/pubmed/28902911

17. Yazdani A, Dorri S, Atashi A, Shirafkan H, Zabolinezhad H. Bone Metastasis Prognostic Factors in Breast Cancer. Breast Cancer Basic Clin. Res. 2019; 13: 117822341983097.

PubMed: https://www.ncbi.nlm.nih.gov/pubmed/30828246 
18. Van Hoof VO, Van Oosterom AT, Lepoutre L, De Broe ME. Alkaline phosphatase isoenzyme patterns in malignant disease. Clin Chem. 1992; 32: 2546-2551.

PubMed: https://www.ncbi.nlm.nih.gov/pubmed/1458597

19. Stieber $P$, Nagel D, Ritzke $C$, Rossler N, Kirsch C, et al. Significance of bone alkaline phosphatase, CA 15-3 and CEA in the detection of bone metastases during the follow-up of patients suffering from breast carcinoma. Eur J Clin Chem Clin Biochem. 1992; 30: 809-814. PubMed: https://www.ncbi.nlm.nih.gov/pubmed/1489855

20. Ramaswamy G, Rao VR, Krishnamoorthy L, Ramesh G, Gomathy R, et al. Serum levels of bone alkaline phosphatase in breast and prostate cancer with bone metastasis. Indian J Clin Biochem. 2000; 15: 110-113. PubMed: https://www.ncbi.nlm.nih.gov/pubmed/23105250

21. Lamerz R, Stieber $P$, Fateh-Moghadam A. Serum marker combinations in human breast cancer (review). In vivo (Brooklyn). 1993; 7: 607-613. PubMed: https://www.ncbi.nlm.nih.gov/pubmed/8193281
22. Coombes R, Powles TJ, Gazet JC, Nash AG, Ford HT, et al. Assessment of biochemical tests to screen for metastases in patients with breast cancer. Lancet. 1980; 1: 296-298.

PubMed: https://www.ncbi.nlm.nih.gov/pubmed/6101748

23. Chandrakanth K, Kpyati A, Murthy DJ. Significance of serum total alkaline phosphatase levels in breast cancer. Int $\mathrm{J}$ Clin Biomed Res. 2016; 2: 13-15.

24. Faiz AS, Guo S, Kaveney A, Philipp CS. Venous thrombosis and breast cancer in older women: Racial differences in risk factors and mortality. Thromb Res. 2018; 171: 130-135.

PubMed: https://www.ncbi.nlm.nih.gov/pubmed/30296717

25. Han LJ, Seong-wook L. The Roles of Carcinoembryonic Antigen in Liver Metastasis and Therapeutic Approaches. Gastroenterol Res Pract. 2017; 2017: 11.

PubMed: https://www.ncbi.nlm.nih.gov/pubmed/28588612 